\title{
A Comparative Evaluation of GIS based Flood Susceptibility Models: A Case of Kopai River Basin, Eastern India
}

\section{Ranajit Ghosh}

Suri Vidyasagar College

\section{Subhasish Sutradhar}

Raiganj University

Niladri Das ( $\nabla$ niladridas123@gmail.com )

Hiralal Bhakat College https://orcid.org/0000-0003-2032-7855

Prolay Mondal

Raiganj University

\section{Research Article}

Keywords: Weight of evidence, Shannon entropy, Frequency ratio, flood susceptibility, Receiver Operating Characteristics curve

Posted Date: July 19th, 2021

DOl: https://doi.org/10.21203/rs.3.rs-705204/v1

License: (9) This work is licensed under a Creative Commons Attribution 4.0 International License. Read Full License 
A comparative evaluation of GIS based flood susceptibility models: a case of Kopai river basin, Eastern India

\author{
Ranajit Ghosh ${ }^{1}$, Subhasish Sutradhar ${ }^{2}$, Niladri Das ${ }^{3^{*}}$, Prolay Mondal $^{2}$ \\ ${ }^{2}$ Department of Geography, Raiganj University, Raiganj, Uttar Dinajpur, 733134, India, \\ ${ }^{1}$ Department of Geography, Suri Vidyasagar College, Suri, Birbhum, West Bengal, 731101, \\ India \\ ${ }^{3}$ Department of Geography, Hiralal Bhakat College, Nalhati, Birbhum, West Bengal, 731220, \\ India, \\ +91-8436181140, Email: niladridas123@ gmail.com \\ Orcid id: https://orcid.org/0000-0003-2032-7855
}

*Corresponding author 


\title{
A comparative evaluation of GIS based flood susceptibility models: a case of Kopai river basin, Eastern India
}

\begin{abstract}
Flood is a typical natural disaster which every year causes enormous damage to the natural environment, buildings and victims worldwide. The efficiency of flooding depends upon numerous criteria: flood strength, amplitude, frequency, flow time, changes in plan and river geometry, etc. In this research, three statistical models such as the frequency ratio, Shannon's entropy, and weight of evidence have been used to identify flood susceptibility regions in the Kopai River Basin. In order to run these statistical models, flooded and nonflooded pixels were employed. The outcome of these three models demonstrates that the upper reach of the basin is characterised by non-flooded zones and the bottom reach of the basin is high flooded zones. The lower part of the basin is therefore more vulnerable than that of the upper portion. 11 thematic layers are employed to get the final output of flood susceptibility zones. e.g., soil type, normalised vegetation difference index, normalised water differential index, river lift, slope, drainage density, land usage and land cover, rainfall, soil moisture indices, surface roughness. 370 sample points have been taken as test data and finally receiver operating curves have been plotted for testing the degree of accuracy. The result of the validation reveals that the accuracy of the frequency ratio is $96.5 \%$. Shannon entropy is $91.2 \%$ accurate and the weight of evidence is $97.1 \%$ accurate. Weight of evidence is therefore the best model for flood susceptibility zones identification for this Kopai basin.
\end{abstract}

Keywords: Weight of evidence, Shannon entropy, Frequency ratio, flood susceptibility, Receiver Operating Characteristics curve

\section{Introduction}

Every year, many natural and man-induced hazards and calamities are witnessed across the globe such floods, earthquakes, landslides, etc. (Youssef et al. 2011; Du et al. 2013; Tehrany et al. 2014a; WHO 2019). However, the trend has recently increased significantly because to numerous variables, such as climate change, deterioration of the ecosystem, fast population 
1 expansion, etc. (Caruso 2017). Among these, floods are one of the most prevalent and destructive

2 natural catastrophes, resulting in substantial financial damage and the loss of lives every year all

3 over the globe. (Kowalzig 2008; Kourgialas and Karatzas 2011). Floods, in addition to these

4 factors, play a significant role in causing destruction on the environment's ecology. (Billa et al.

5 2006; Rahmati et al. 2015, 2016). Globally, 31\% of economic damage is occurred due to this

6 natural disaster (Yalcin and Akyurek 2000). Floods generally occur when significant volumes of

7 water exceed the usual limits, riverside submerges and causes stagnant water during the fleeting

8 season.

$9 \quad$ Furthermore, floods in India are more prevalent among all other natural disasters. Around the one-eighth geographic region of this nation, over 40 million hectares of land are at danger of

11 flood. (Gupta et al. 2003; Mohapatra and Singh 2003). In India, flood-prone areas have increased

12 significantly at a rate of 0.14 million hectares per year (Singh and Kumar 2013). The Ganga and

13 Brahmaputra are the most chronic flood-prone basins covering northern and north-eastern states

14 of this country. During the monsoon, most floods occur because to the seasonal and temporal

15 variations in rainfall patterns, which lead to a lot of flux from rivers during this time. (Kumar et

16 al. 2005). In addition to this, siltation on riverbeds, insufficient capacity on river banks to hold

17 high flow, change in river course, break down of dams, poor drainage condition in flood-prone

18 areas, and glacial outbursts are other responsive factors of flood occurrence. Every year, around

1930 million people in this nation experience the flood, more than 1500 of them perish. (Gupta et

20 al. 2003). In terms of the flood, India's position is second, just after Bangladesh, due to its flat

21 topography, shallow river bed, monsoonal rainfall variation, massive sediment discharge, etc.

22 (Sarkar and Mondal 2020). Identifying flood-prone locations is thus the most important activity

23 of scientists to prevent loss of life and property. Many scientific research has been carried out in 
1 order to classify and identify various kinds of floods and their immediate and long-term

2 repercussions.

Flood sensitivity mapping refers to the quantitative or qualitative assessment and

4 classification of the spatial distribution of floods, which may exist or potentially occur in an area.

5 Consequently, techniques for flood susceptibility mapping and flood vulnerability assessment

6 may without doubt assist policy makers and authorities involved in drawing up requirement

7 plans and policies. Although the occurrence of flood risk cannot be eliminated, flood damage

8 may be prevented or minimised greatly by recognising flood-prone locations effectively (Sahoo

9 and Sreeja 2017). Therefore, flood sensitivity assessment is a crucial work for disaster remission,

10 although this will be challenging work due to the direct and indirect involvement of many

11 conditioning factors. In recent years, researchers have suggested, so many broader models for

12 flood risk assessment incorporate remote sensing and GIS tools, which provided considerable

13 good accuracy (Pradhan 2009; Bates 2012; Wanders et al. 2014; Nikoo et al. 2016). Most of the

14 previously used models were mainly focused on the hydrodynamic model, hydrological model,

15 multi-criteria decision analysis (MCDA), statistical models (SM), and machine learning (ML)

16 techniques, which are incorporated in the geographic information system (Singh and Kumar

17 2013; Pradhan 2014; Elkhrachy 2015; Vojtek and Vojteková 2016; Rosser et al. 2017; Samanta

18 et al. 2018; Tiryaki and Karaca 2018; Liuzzo et al. 2019; Santos et al. 2019; Tehrany et al.

19 2019a; Shahabi et al. 2020). The most commonly used models and techniques concerning flood

20 susceptibility mapping include frequency ratio (FR) (Rahmati et al. 2015; Shafapour Tehrany et

21 al. 2017; Samanta et al. 2018; Tehrany et al. 2019a; Sarkar and Mondal 2020), analytical

22 hierarchy process (AHP) (Elkhrachy 2015; Dahri and Abida 2017; Das 2018; Rahman et al.

23 2019; Sepehri et al. 2020a), shannon's entropy (Khosravi and Pourghasemi 2016; Haghizadeh et 
1 al. 2017), weights of evidence (WoE) (Tehrany et al. 2014b; Rahmati et al. 2015; Shafapour

2 Tehrany et al. 2017; Costache 2019), artificial neural networks (ANN) (Kia et al. 2012; Ruslan et

3 al. 2013; Elsafi 2014; Rahman et al. 2019; Kordrostami et al. 2020), fuzzy logic (Nandalal and

4 Ratnayake 2011; Sahana and Patel 2019; Sepehri et al. 2020b), support vector machines

5 (Tehrany et al. 2014b, 2015, 2019b; Nandi et al. 2017), biogeography based optimization and

6 BAT algorithms (Ahmadlou et al. 2018; Wang et al. 2019), adaptive neuro-fuzzy inference

7 system (ANFIS) (Wang et al. 2019; Vafakhah 2020), reduced error pruning trees (Khosravi et al.

8 2018), multivariate adaptive regression splines (Tien et al. 2019), maximum entropy

9 (Haghizadeh and Rhamti 2017), random forest (Lee et al. 2017; Reza et al. 2020) etc.

The present study of flood vulnerability assessment has been done through frequency

11 ratio (FR), weights of evidence (WoE), and shannon's entropy (SE) models. The previously used

12 literature section reveals that these are the most useful statistical models for not only flood

13 vulnerability assessment but also landslide vulnerability mapping. In this study, several

14 parameters, i.e., Soil type, Normalized Difference Vegetation Index (NDVI), Normalized

15 Difference Water Index (NDWI), Distance to River, Elevation, Slope, Drainage Density, Land

16 use and Land cover, Rainfall, Soil Moisture Index (SMI), and Surface Roughness have been used

17 for flood vulnerability assessment. In several previous studies, these selected parameters (Table

18 1) have been used to identify flood vulnerable zones and susceptibility mapping by different

19 researchers. For this study, three models have been chosen instead of one because only one

20 model will not be adequate to predict susceptible flood zone. Many research works confirms that

21 most of these are site-specific models and each of these models has some specific advantages

22 and disadvantages. Therefore, the main objective of this work is to develop a unique flood risk 
1 map of this study area and to achieve a best-fitted model considering these supreme performing

2 models.

3

4

Table $1[$ Near here]

\section{Materials and methods}

6

This portion describes the data gathered and used, as well as the theoretical concept of the

7 flood susceptibility modeling approaches. The data was prepared and evaluated to create

8 databases for constructing and validating models, which included a flood vulnerability map and

9 flood conditioning variables. To assess flood susceptibility, bivariate models (FR, SE, and WoE)

10 were used, and validation methods (ROC and AUC) were chosen to check the bivariate models'

11 effectiveness.

$12 \quad$ Location of the study area

13 Kopai river basin is one of the important river basin in Rarh Bengal. The source of the

14 river is Khajuri village, Jharkhand and its confluence is Babla river, Murshidabad. The total area

15 of the basin is about $1533 \mathrm{Km}^{2}$ and the total length of the river is about $176 \mathrm{Km}$. The latitudinal

16 extension of the basin is from $23^{\circ} 26^{\prime} 18^{\prime \prime}$ North to $23^{\circ} 56^{\prime} 30^{\prime \prime}$ North and longitudinal extension is

17 from $87^{\circ} 13^{\prime} 00^{\prime \prime}$ East to $88^{\circ} 09^{\prime} 30^{\prime \prime}$ East. The location of the Kopai river basin has been shown in

18 Fig. 1

19

20

Fig.1 [Near here]

21

$22 \quad 2.2$ Flood Inventory Map 
2 foothold in the phase of the creation of flood inventory map. In order to forecast potential

3 flooding, the accuracy of data from previous and current floods is important. Not only did the

4 Desk Research, but even the field research was done. At first, the aerial photos of the region

5 were used to prepare an inventory of the flood risk zones, and this was inspected during field

6 verification. The study area's 274 flooded areas were identified and mapped from an aerial photo

7 analysis of the entire region. A field experiment was used to locate and verify these coordinates.

8 Fig. 2 depicts the site locations of 274 inundated areas. 192 (two-to-thirds) 82 (one-to-thirds) of 9 these points were picked from the random dataset for modeling, and the remaining 82 (one-to10 thirds) points acted as reference points for the model's accuracy.

Fig. 2[Near here]

\subsection{Modeling of Flood Susceptibility}

\subsubsection{Frequency Ratio Model}

The Frequency Ratio (FR) is an observation-based model since it has a clear and intuitive

17 description, as well as it is precise, and is used in a large variety of research applications, making 18 it a good tool for planning flood susceptible maps. The FR approach is based on observed 19 correlations between the distribution of flood incidence locations and each of the variables that 20 influence floods, and it is used to uncover the association between them. The FR model is 21 interpreted mathematically as follows:

$$
F R=\frac{N_{P i x(F i)} / N_{P i x(N i)}}{\sum N_{P i x(F i)} / \sum N_{P i x(N i)}} .
$$


Where, The number of pixels containing flood in class $\mathrm{i}$ is represented by $\mathrm{N}_{\text {pix(Fi), and }}$

$3 \mathrm{~N}_{\mathrm{pix}(\mathrm{Ni})}$ is used to reflect the total number of pixels in class $\mathrm{i}$. The degree of association between

4 flood and the concerned class of conditioning variables is expressed by the measured value of

5 FR. A value greater than 1 indicates a good and favorable association as well as high flood susceptibility, while a value less than 1 indicates a detrimental interaction as well as low flood

7 susceptibility. The FR of each class was subsequently summarized using the given formula 8 equation to determine the Flood Susceptibility Index (FSI):

\subsubsection{Shannon's Entropy Model}

Entropy is a methodological approach that is used in a framework to avoid abnormality, instability, disruption, and uncertainty. In 1948, Shannon developed the entropy model, which Stephan Boltzmann introduced to quantify the disorderliness of thermodynamic systems, and this concept has since been used to measure inhomogeneity in the distribution of variable values. This approach can also be used in the flood susceptibility analysis using the concept of entropy.

17 Using the following equations, Shannon's Entropy Model has been structured:

$$
P_{i j}=\frac{F R}{\sum_{j=1}^{N j} F R}
$$

$$
H_{\text {jmax }}=\log _{2} N j
$$

$$
I_{j}=\left(H_{j \max }-H_{j} / H_{\text {jmax }}\right), I=(0,1), j=1, \ldots, n \ldots .
$$


$\mathrm{H}_{\mathrm{j}}$ and $\mathrm{H}_{\mathrm{jmax}}$ represent entropy values, $\mathrm{I}_{\mathrm{j}}$ depicts information coefficient, and $\mathrm{W}_{\mathrm{j}}$ refers to

3 resultant weight values for each parameter.

$4 \quad$ Now the $\mathrm{W}_{\mathrm{j}}$ of each class was subsequently summarized using the given formula 5 equation to determine the Flood Susceptibility Index (FSI):

$$
F S I=\sum W_{j} P_{i j}
$$

\section{$7 \quad 2.3 .3$ Weight of Evidence Model}

It is a quantitative "data-driven" approach for predicting the frequency of incidents based prepare a flood susceptibility map (Tehrany et al. 2014b; Rahmati et al. 2015; Shafapour Tehrany et al. 2017; Costache 2019). The statistical association between flood locations and each

12 conditioning factor can be calculated by overlaying flood locations with each influencing factor 13 and determining if and how significantly the effective factor is responsible for previous floods.

14 This model is built on the concept of determining positive and negative weights. In this method, 15 positive and negative weights have been calculated based on the weight for each flood conditioning factor (A) based on the presence or absence of the floods (B) within the specific

17 area as follows:

$$
W_{i}^{+}=\ln \frac{P\{B \mid A\}}{P\{B \mid A\}}
$$

$$
W_{i}^{-}=\ln \frac{P\{\bar{B} \mid A\}}{P\{\bar{B} \mid \bar{A}\}}
$$


1 and absence by $\bar{B}$. A positive weight $\left(\mathrm{W}_{\mathrm{i}}^{+}\right)$demonstrates that the influencing factor is prevalent

2 in flooded areas and that it is a representation that the existence of the conditioning factor and

3 floods are correlated in a positive way. On the other hand, the non-existence of the influencing

4 factors represented by negative weight $\left(\mathrm{W}_{\mathrm{i}}^{-}\right)$.

$$
C=W^{+}+\mathrm{W}^{-}
$$

6

Where $C$ reflects all positive and negative spatial relationships dependent on positive and negative values in this statistical equation. Now, $\mathrm{S}(\mathrm{c})$, which is the standard deviation of positive and negative weights, is calculated as follows:

$$
S(C)=\sqrt{S^{2}\left(W^{+}\right)+S^{2}\left(W^{-}\right)}
$$

The variance of the positive and negative weights is described by S2(W+) and S2 (W), respectively. The following equation may be used to measure the weights' variance (BonhamCarter 1994).

$$
\begin{aligned}
S^{2}\left(W^{+}\right) & =\frac{1}{N\{B \cap A\}}+\frac{1}{B \cap \bar{A}} \ldots \ldots \ldots \ldots \ldots \ldots \ldots \ldots \\
S^{2}\left(W^{-}\right) & =\frac{1}{\{\bar{B} \cap A\}}+\frac{1}{\bar{B} \cap \bar{A}} \ldots \ldots \ldots \ldots \ldots \ldots \ldots \ldots
\end{aligned}
$$

The final weight is represented by the studentized constant, which is described as the ratio between contrasts and standard deviation.

$$
W_{\text {final }}=\left(\frac{C}{S(C)}\right) \ldots \ldots \ldots \ldots \ldots \ldots \ldots \ldots \ldots \ldots \ldots
$$

After calculating the model's final weights, a flood susceptibility map can be produced using FSI values. FSI values have been calculated using the following formula:

$$
F S I=\sum W_{\text {final }}
$$


Numbers of thematic maps have been developed to produce the flood susceptibility map.

2 For this purpose, Soil type, Normalized Difference Vegetation Index (NDVI), Normalized Difference Water Index (NDWI), Distance to River, Elevation, Slope, Drainage Density, Land

$4 \quad$ use and Land cover, Rainfall, Soil Moisture Index (SMI), and Surface Roughness has been used 5 for flood vulnerability assessment. Each factor has individual importance over the preparation of 6 the final output.

7 a. Rainfall: It is one of the main influencing parameters to accelerate flood phenomena (Rahman et al. 2019). Heavy rainfall occurrences can be observed in the upper reach of

the basin, where $>1400 \mathrm{~mm}$ rainfall has been recorded annually. Contrary, the lowest rainfall occurs along the lower reach of the basin where annually $<1200 \mathrm{~mm}$ rainfall has been recorded (Fig. 3i). Thus, though the highest rainfall was recorded in the upper reach, the highest flood has been recorded in the lower reach. So, here slope plays a vital role in the accelerating flood.

b. Elevation and Slope: Land elevation and slope are the second most crucial flood susceptibility influencing factors as they control runoff of a river basin (Rahman et al. 2021). Runoff generally occurs from highland to lowland; thus, flood probability is highest in the lower reach of a basin. The highest elevation of the test region ranges between 110-160 meters in the western part of the basin, but the basin experiences 16-38 meters as the lowest elevation in the eastern part (Fig. 3a).

If we consult the degree of slope, it can be observed that the western part has been experienced by $2.64-27.94 \%$ of the slope, but the eastern part where the elevation is lowest has been characterized by $0.98 \%$ of slope (Fig. 3b). 
c. Land use and Land cover: The land use pattern for an area shows the kind of land use by living populations and natural processes (Ajin et al. 2013; Kaur et al. 2017). Land use and land cover maps are critical in determining flood risk, as vegetated areas are less vulnerable to flooding events due to the negative association between a flooding event and vegetation density (Mojaddadi et al. 2017). LULC directly affects When combined, these characteristics provide details about the hydrological response and the degree of flood threat (Islam and Sado 2000).

d. Soil type: Different types of soil influence the degree of flood susceptibility (Costache 2019; Dano et al. 2019; Das 2019; Rahman et al. 2021) as the soil form affects an area's ability to retain water (Asare-Kyei et al. 2015; El Morjani et al. 2017). Fig. 3g depicts that the name of the soil classes has been given as per their location, and based on locational nomenclature, Ghoshgram-Gourbazar soil is predominant here.

e. Distance to the river: Flooding is a common phenomenon along the stream in the research

region.

Distance to the river was also considered another element relevant to geomorphology. A distance from the river map was subsequently created as the rivers would disturb the stabi lity of the slopes either by cutting the toes or by saturating the pieces of material lying wit hin the river (Mojaddadi et al. 2017; Shafapour Tehrany et al. 2017; Rahman et al. 2019). Distance from the river or proximity map has been prepared in ArcGIS 10.5 software (evaluation version) using the Euclidean distance method. Fig. 3e reveals five proximity zones or five buffer zones from the mainstream. There is an inverse relationship between distance from mainstream and flood occurrences; increasing the distance from the river, flood susceptibility becomes decreased and vice-versa. 
f. Drainage Density: Increased flooding probability is closely correlated with increased drainage density, as it implies increased surface runoff. It has been indicated that areas with a higher drainage level produce more surface runoff than areas with a low drainage density (Kumar et al. 2007). Thus, the extent to which flood risk increases can be dependent on drainage density, a key factor in runoff production (Ogden et al. 2011). A drainage density map has been prepared in ArcGIS 10.5 (evaluation version) using the grid method. Fig. 3d shows that higher drainage density present in the upper reach of the basin but lower drainage density in the lower reach of the basin. Due to the slope factor, flood susceptibility is high in the lower reach despite lower drainage density.

g. Normalized Difference Vegetation Index (NDVI): Intensity of flood and flood susceptibility has been associated with vegetation cover (Ajin et al. 2013; Kaur et al. 2017; Rahman et al. 2021). Normalized Difference Vegetation Index or NDVI has been derived from LANDSAT-8 imagery in Arc GIS 10.5 software (evaluation version) using the raster calculator tool. To get the final output of NDVI from Landsat-8 imagery following formula has been used.

$$
\mathrm{NDVI}=\frac{(\text { NIR band }-R \text { band })}{(\text { NIR band }+R \text { band })}
$$

Fig.3J shows that the upper reach has been characterized by dense vegetation due to a high degree of the slope, but the lower reach has sparse vegetation cover.

\section{h. Normalized Difference Water Index (NDWI): Normalized Difference Water Index or} NDWI refers to the data of liquid water derived from the satellite images. It locates all the water bodies present on the surface, directly affecting the inundation period and frequency of flood (Memon et al. 2015; Khalifeh Soltanian et al. 2019; Sivanpillai et al. 2020). NDWI has been derived from Landsat-8 satellite imagery in ArcGIS 10.5 software 
(evaluation version) using the raster calculator tool. The following formula has been used to calculate NDWI.

$$
\text { NDWI }=\frac{(\text { Green } \text { band }- \text { NIR band })}{(\text { Green band }+ \text { NIR band })}
$$

NDWI values range from -1 to 1 . The NDWI value for water bodies is more significant than 0.5 , while lower values, such as negative values, equate to plants, making it simple to differentiate water bodies from vegetation. Fig. $3 \mathrm{~K}$ reveals the spatial pattern of NDWI.

i. Soil Moisture Index (SMI): Soil moisture plays an important role in the regulation of the water cycle and flood inundation period (Saha et al. 2018). If soil contains high moisture and even it receives further rainfall, soil cannot hold more water. As a result, overflow occurs around the land areas, ultimately converting to flood (Beran and Sutcliffe 1972; Ahlmer et al. 2018). The soil moisture index of SMI has been derived from LANDSAT 8 satellite imagery using the following formula in ArcGIS software.

$$
\mathrm{SMI}=\frac{(\text { LST Max }-L S T)}{(\text { LST Max }-L S T \text { Min })}
$$

Where LST Max means Maximum land Surface Temperature LST Min means Minimum land Surface Temperature Fig. 3h depicts maximum soil moisture is present in the lower reach of the river basin; that's why flood intensity is maximum in the lower reach. 
j. Surface Roughness: It is another factor that affects flood susceptibility differently. More the roughness in the surface, flood susceptibility becomes reduced and vice-versa. This parameter is a Digital elevation model or DEM derived factor, and this map has been prepared using ArcGIS 10.5 software (evaluation version) and it is smooth in the lower reach.

Fig. 4 [Near here]

\subsection{Frequency ratio and flood susceptibility zones}

Eleven parameters have been taken to run the frequency model. Table 3 shows the

19 frequency ratio value for all parameters and associated feature classes. Here higher the values of 20 frequency ratio, the higher will be flood susceptibility and vice-versa. Therefore, a strong 21 positive relationship prevails between FR values and flood intensity (Liuzzo et al. 2019). The 22 outcome of FR model is strongly related to elevation and drainage density (Fig...5a, 3a, and 3d). 23 So, it can be easily explained that the number of flood occurrences as per the frequency model 
1 depends on the elevation and drainage density factor. Fig.5a reveals, as per the FR model, high

2 flood susceptibility zones present in the lower reach of the basin and low to very low flood

3 susceptibility exists in the upper reach of the Kopai river basin. Moreover, soil moisture index is

4 also an important influencing parameter for flood occurrence as per the FR model. If we

5 observed Fig. (3h) and Fig. (5a), both resemble at the lower reach where river basin holds

6 excessive moisture, and it accelerates high flood susceptibility. In this model, high and very high

7 flood suspectable zones acquire 362.403 and $191.184 \mathrm{Km}^{2}$ area (Table2)

$9 \quad 3.2$ Shannon's Entropy and flood susceptibility zones

Shannon's entropy is another statistical model has been applied here to extract the flood

11 susceptibility zones of Kopai river basin. Detail methodology of this model has been discussed in

12 the methodology section. The result of Shannon's entropy has been depicted in Fig. 5b. This

13 figure has been clearly shown that the area high flood susceptibility zones are much larger than

14 FR model, and also this model reveals the larger absence of very low susceptibility, e.g., in

15 Shanno's model high and very high flood suspectable zones contain 522.757 and $314.266 \mathrm{Km}^{2}$

16 area in respect to FR model (Table2). So, this model gives a different result than FR model.

17

\subsection{Weight of Evidence and flood susceptibility zones}

Fig. 5c explains that this model more or less similar to the FR model. Both FR and WOE

20 show the same areal coverage of flood susceptibility zones (Table2). This model shows the lower

21 reach of the Kopai river basin is more susceptible to flood than the upper reach.

There is a similarity of these three models, i.e., for each model highest value indicates

23 high flood susceptibility and vice-versa. 
Fig. 5 [Near here]

4

\subsection{Validation of models}

For the validation of these three models, the receiver operating curve or ROC has been applied. The AUROC curve was utilized in this work to depict and evaluate the predictive capability of standalone models. The AUROC diagram is constructed by graphing the sensitivity on the $\mathrm{x}$-axis against the 1-specificity on the y-axis. The AUROC curve quantitatively illustrates model prediction capability and map accuracy. The AUROC and prediction accuracy connection

11 fluctuates between 0 and 1, and was divided into five categories (Wang et al. 2011) viz. >0.9 to 1

12 perfectly applicable, 0.8 to 0.9 highly applicable 0.7 to 0.8 moderately applicable 0.6 to 0.7

13 Poorly applicable 0.5 to 0.6 very poorly applicable. For ROC drawing, more than 300 sample

14 points have been taken as test files, and the test points have been selected to identify where the 15 susceptible zones are really flooded or not. With the help of these 300 selected ground points, we 16 have tried to judge the reality of flood and non-flooded zones in the concerning test area. If we 17 look at Fig. 6, it depicts three ROC curves for three respective models like FR model, Shannon's 18 entropy, the weight of evidence. Three models give three different results: AUC of FR, 19 Shannon's entropy, and WOE are 0.965, 0.912, and 0.971, respectively (Fig.6). 

applicable statistical models in this region than Shannon's entropy. If we observed the output of

3 flood susceptibility zones, it would be clear that Shannon's entropy gives more flooded regions

4 than the other two models, but in reality, the Kopai river basin holds flooded areas only in the

5 lower reach. As the ROC curve has been depicted based on field data, the validation result of

6 Shannon's entropy failed for the proper explanation of flood susceptibility than FR and WOE

7 model. Here WOE gives a more accurate result than the other two models, and it provides $97 \%$

8 accuracy. So, we accept the weight of evidence as a valid model to identify the flood

$9 \quad$ susceptibility zones for this particular river basin.

\section{2. Conclusion}

This study proposed flood susceptibility zones based on three statistical models. To run the three models, 10 flood influencer parameters have been taken into consideration. For each

14 model same parameters have been selected to get the comparative result. Three models give uniform results in the sense that in all models upper reach of the basin displayed lower flood susceptible zones, and the lower reach give higher susceptible zones. These five zones have been 17 identified to show the intensity of flood susceptibility viz. very high susceptible, high susceptible, moderately susceptible, low susceptible, and very low susceptible.

In terms of validation of the model, we can observe that the weight of evidence gives more accuracy than the other two models, e.g., frequency ratio and Shannon's entropy. ROC has

21 been plotted here to identify the curve and accuracy of the model, where WOE method depicts more than $97 \%$ accuracy compared to other consecutive methods. 

this research could be a valuable resource for engineers, policymakers, planners, and

3 administrative organizations. Another notable difference is that the methodologies used in this

4 study bridge the gap of comprehending catastrophic floods and their effectiveness. This

5 methodology is advised for providing a greater understanding of the magnitude and frequency of

6 floods as well as the area where people are at risk for floods.

7

8 Funding: The authors received no specific funding for this work.

9 Ethical Conduct: The manuscript includes no issue related to ethical compliance.

\section{References}

13 Ahlmer AK, Cavalli M, Hansson K, et al (2018) Soil moisture remote-sensing applications for 14 identification of flood-prone areas along transport infrastructure. Environ Earth Sci 77:117. https://doi.org/10.1007/s12665-018-7704-Z

Ahmadlou M, Karimi M, Alizadeh S, et al (2018) Flood susceptibility assessment using integration of adaptive network-based fuzzy inference system ( ANFIS ) and biogeographybased optimization ( BBO ) and BAT algorithms ( BA ). Geocarto Int 6049:1-37. https://doi.org/10.1080/10106049.2018.1474276

Ajin RS, Krishnamurthy RR, Jayaprakash M, Vinod PG (2013) Flood hazard assessment of techniques. Adv Appl Sci Res 4:263-274 
1 Asare-Kyei D, Forkuor G, Venus V (2015) Modeling flood hazard zones at the sub-district level

2 with the rational model integrated with GIS and remote sensing approaches. Water

3 (Switzerland) 7:3531-3564. https://doi.org/10.3390/w7073531

4 Bates PD (2012) Integrating remote sensing data with flood inundation models: How far have we

5 got? Hydrol Process 26:2515-2521. https://doi.org/10.1002/hyp.9374

6 Beran MA, Sutcliffe J V (1972) Data The daily rainfall available for the study comprise the long 7 term records Analytical procedure It would be possible to study rainfall excess for those $8 \quad$ stations and periods. 17:229-236

9 Billa L, Shattri M, Mahmud AR, Ghazali AH (2006) Comprehensive planning and the role of

Bonham-Carter GF (1994) Geographic Information Systems for Geoscientists Modelling with GIS. Pergamon

Caruso GD (2017) The legacy of natural disasters: The intergenerational impact of 100 years of disasters in Latin America. J Dev Econ 127:209-233. https://doi.org/10.1016/j.jdeveco.2017.03.007

Costache R (2019) Flash-flood Potential Index mapping using weights of evidence, decision Trees models and their novel hybrid integration. Stoch Environ Res Risk Assess 33:13751402. https://doi.org/10.1007/s00477-019-01689-9

Dahri N, Abida H (2017) Monte Carlo simulation-aided analytical hierarchy process ( AHP ) for flood susceptibility mapping in Gabes Basin ( southeastern. Environ Earth Sci 76:1-14. 
Dano UL, Balogun A, Matori A, et al (2019) Flood Susceptibility Mapping Using GIS-Based Analytic Network Process : A Case Study of. https://doi.org/10.3390/w11030615

Das S (2018) Geographic information system and AHP-based flood hazard zonation of Vaitarna basin, Maharashtra, India. Arab J Geosci 11:. https://doi.org/10.1007/s12517-018-3933-4

Das S (2019) Remote Sensing Applications : Society and Environment Geospatial mapping of flood susceptibility and hydro-geomorphic response to the floods in Ulhas basin, India. Remote Sens Appl Soc Environ 14:60-74. https://doi.org/10.1016/j.rsase.2019.02.006

Du J, Fang J, Xu W, Shi P (2013) Analysis of dry/wet conditions using the standardized precipitation index and its potential usefulness for drought/flood monitoring in Hunan Province, China. Stoch Environ Res Risk Assess 27:377-387. https://doi.org/10.1007/s00477-012-0589-6

El Morjani ZEA, Seif Ennasr M, Elmouden A, et al (2017) Flood hazard mapping and modeling using GIS applied to the Souss River watershed. Handb Environ Chem 53:57-93. https://doi.org/10.1007/698_2016_69

Elkhrachy I (2015) Flash Flood Hazard Mapping Using Satellite Images and GIS Tools : A case study of Najran City, Kingdom of Saudi Arabia ( KSA ). Egypt J Remote Sens Sp. https://doi.org/10.1016/j.ejrs.2015.06.007

Elsafi SH (2014) Artificial Neural Networks ( ANNs ) for flood forecasting at Dongola Station in the River Nile ,. Alexandria Eng J 53:655-662. https://doi.org/10.1016/j.aej.2014.06.010

Gupta S, Javed A, Datt D (2003) Economics of Flood Protection in India. 199-210 
1 Haghizadeh A, Rhamti O (2017) Spatial prediction of flood-susceptible areas using frequency ratio and maximum entropy models. Geocarto Int 6049:0-1. https://doi.org/10.1080/10106049.2017.1316780

Haghizadeh A, Siahkamari S, Haghiabi AH, Rahmati O (2017) Forecasting flood-prone areas using Shannon’s. https://doi.org/10.1007/s12040-017-0819-X

Islam M, Sado K (2000) Development of flood hazard maps of Bangladesh using NOAAAVHRR images with GIS / Mise au point des cartes d'exposition au risque de crue du Bangla Desh a l'aide d'images NOAA AVHRR et d'un SIG. Hydrol Sci J 45:337-355

Kaur H, Gupta S, Parkash S, et al (2017) Geospatial modelling of flood susceptibility pattern in a subtropical area of West Bengal, India. Environ Earth Sci 76:. https://doi.org/10.1007/s12665-017-6667-9

Khalifeh Soltanian F, Abbasi M, Riyahi Bakhtyari HR (2019) Flood monitoring using ndwi and mndwi spectral indices: A case study of aghqala flood-2019, Golestan Province, Iran. Int Arch Photogramm Remote Sens Spat Inf Sci - ISPRS Arch 42:605-607. https://doi.org/10.5194/isprs-archives-XLII-4-W18-605-2019

Khosravi K, Pourghasemi HR (2016) Flash flood susceptibility analysis and its mapping using different bivariate models in Iran : a comparison between Shannon's entropy, statistical index , and weighting factor models. Environ Monit Assess. https://doi.org/10.1007/s10661016-5665-9

Khosravi K, Thai B, Chapi K, et al (2018) Science of the Total Environment A comparative assessment of decision trees algorithms for fl ash fl ood susceptibility modeling at Haraz 
1

watershed , northern Iran. Sci Total Environ 627:744-755. https://doi.org/10.1016/j.scitotenv.2018.01.266

Kia MB, Pirasteh S, Pradhan B, et al (2012) An artificial neural network model for flood simulation using GIS : Johor River Basin , Malaysia. 251-264. https://doi.org/10.1007/s12665-011-1504-z

Kordrostami S, Alim MA, Karim F, Rahman A (2020) Regional Flood Frequency Analysis Using An Artificial Neural Network $\quad$ Model. https://doi.org/10.3390/geosciences 10040127

Kourgialas NN, Karatzas GP (2011) Gestion des inondations et méthode de modélisation sous SIG pour évaluer les zones d'aléa inondation-une étude de cas. Hydrol Sci J 56:212-225. https://doi.org/10.1080/02626667.2011.555836

Kowalzig J (2008) Climate, Poverty, and Justice: What the Poznan UN climate conference needs to deliver for a fair and effective global deal. Oxfam Policy Pract Clim Chang Resil 4:117148

Kumar PKD, Gopinath G, Seralathan P (2007) Application of remote sensing and GIS for the demarcation of groundwater potential zones of a river basin in Kerala, southwest coast of India. Int J Remote Sens 28:5583-5601. https://doi.org/10.1080/01431160601086050

Kumar R, Singh RD, Sharma KD (2005) Water resources of India. 89:

Lee S, Kim J, Jung H, et al (2017) Spatial prediction of flood susceptibility using random-forest and boosted-tree models in Seoul metropolitan city, Korea. Geomatics, Nat Hazards Risk 0:1-19. https://doi.org/10.1080/19475705.2017.1308971 
1 Liuzzo L, Sammartano V, Freni G (2019) Comparison between Different Distributed Methods

2 for Flood Susceptibility Mapping. 3155-3173

3 Memon AA, Muhammad S, Rahman S, Haq M (2015) Flood monitoring and damage assessment

4

5

6 Mohapatra PK, Singh RD (2003) Flood Management in India. 131-143

7 18:99-106. https://doi.org/10.1016/j.ejrs.2015.03.003 https://doi.org/10.1080/19475705.2017.1294113 https://doi.org/10.1111/j.1753-318X.2011.01097.x Varanasi. Water Resour Manag. https://doi.org/10.1007/s11269-017-1568-y https://doi.org/10.1007/s11069-016-2176-5 using water indices: A case study of Pakistan flood-2012. Egypt J Remote Sens Sp Sci

Mojaddadi H, Pradhan B, Nampak H, et al (2017) Ensemble machine-learning-based geospatial approach for flood risk assessment using multi-sensor remote-sensing data and GIS.

Nandalal HK, Ratnayake UR (2011) Flood risk analysis using fuzzy models. 4:128-139.

Nandi I, Srivastava PK, Shah K (2017) Floodplain Mapping through Support Vector Machine and Optical / Infrared Images from Landsat 8 OLI / TIRS Sensors : Case Study from

Nikoo M, Ramezani F, Hadzima-Nyarko M, et al (2016) Flood-routing modeling with neural network optimized by social-based algorithm. Nat Hazards 82:.

Ogden FL, Raj Pradhan N, Downer CW, Zahner JA (2011) Relative importance of impervious area, drainage density, width function, and subsurface storm drainage on flood runoff from an urbanized catchment. Water Resour Res 47:1-12. 
2 Pradhan B (2009) Flood susceptible mapping and risk area delineation using logistic regression,

3 GIS and remote sensing. J Spat Hydrol 9:1-18

4 Pradhan B (2014) Flood susceptible mapping and risk area delineation using logistic regression , $5 \quad$ GIS and remote sensing Biswajeet Pradhan

6 Rahman M, Chen N, Islam MM, et al (2021) Location-allocation modeling for emergency 7 evacuation planning with GIS and remote sensing: A case study of Northeast Bangladesh. Geosci Front 12:101095. https://doi.org/10.1016/j.gsf.2020.09.022

Rahman M, Ningsheng C, Islam MM, et al (2019) Flood Susceptibility Assessment in 0 Bangladesh Using Machine Learning and Multi-criteria Decision Analysis. Earth Syst

(1)
Environ 3:585-601. https://doi.org/10.1007/s41748-019-00123-y

Rahmati O, Pourghasemi HR, Zeinivand H (2015) Flood susceptibility mapping using frequency ratio and weights-of-evidence models in the Golastan. Taylor Fr 37-41. https://doi.org/10.1080/10106049.2015.1041559

Rahmati O, Zeinivand H, Besharat M (2016) Flood hazard zoning in Yasooj region, Iran, using GIS and multi-criteria decision analysis. Geomatics, Nat Hazards Risk 7:1000-1017. https://doi.org/10.1080/19475705.2015.1045043

Reza A, Islam T, Talukdar S, et al (2020) ur of. https://doi.org/10.1016/j.gsf.2020.09.006

Rosser JF, Leibovici DG, Jackson MJ (2017) remote sensing and topographic data. Nat Hazards. https://doi.org/10.1007/s11069-017-2755-0 
1 Ruslan FA, Zakaria NK, Adnan R (2013) Flood Modelling using Artificial Neural Network. 19-

2

3

4

5

6 20

Saha A, Patil M, Goyal VC, Rathore DS (2018) Assessment and Impact of Soil Moisture Index in Agricultural Drought Estimation Using Remote Sensing and GIS Techniques. Proceedings 7:2. https://doi.org/10.3390/ecws-3-05802

Sahana M, Patel PP (2019) A comparison of frequency ratio and fuzzy logic models for flood susceptibility assessment of the lower Kosi River Basin in India. Environ Earth Sci 78:127. https://doi.org/10.1007/s12665-019-8285-1

Sahoo SN, Sreeja P (2017) Development of Flood Inundation Maps and Quantification of Flood Risk in an Urban Catchment of Brahmaputra River. ASCE-ASME J Risk Uncertain Eng Syst Part A Civ Eng 3:1-11. https://doi.org/10.1061/AJRUA6.0000822

Samanta S, Kumar D, Babita P (2018) Flood susceptibility analysis through remote sensing, GIS and frequency ratio model. Appl Water Sci. https://doi.org/10.1007/s13201-018-0710-1

Santos PP, Reis E, Pereira S, Santos M (2019) A flood susceptibility model at the national scale based on multicriteria analysis. Sci Total Environ 667:325-337. https://doi.org/10.1016/j.scitotenv.2019.02.328

Sarkar D, Mondal P (2020) Flood vulnerability mapping using frequency ratio ( FR ) model : a case study on Kulik river basin, Indo - Bangladesh Barind region. Appl Water Sci. https://doi.org/10.1007/s13201-019-1102-x

Sepehri M, Malekinezhad H, Jahanbakhshi F, et al (2020a) Integration of interval rough AHP and fuzzy logic for assessment of flood prone areas at the regional scale. Acta Geophys. 
2 Sepehri M, Malekinezhad H, Jahanbakhshi F, et al (2020b) Integration of interval rough AHP 3 and fuzzy logic for assessment of flood prone areas at the regional scale. Acta Geophys 68:477-493. https://doi.org/10.1007/s11600-019-00398-9

Shafapour Tehrany M, Shabani F, Neamah Jebur M, et al (2017) GIS-based spatial prediction of flood prone areas using standalone frequency ratio, logistic regression, weight of evidence and their ensemble techniques. Geomatics, Nat Hazards Risk 8:1538-1561. https://doi.org/10.1080/19475705.2017.1362038

Shahabi H, Shirzadi A, Ghaderi K, Omidvar E (2020) Flood Detection and Susceptibility Mapping Using Sentinel-1 Remote Sensing Data and a Machine Learning Approach: Hybrid Intelligence of Bagging Ensemble Based on K-Nearest Neighbor Classifier

Singh O, Kumar M (2013) Flood events, fatalities and damages in India from 1978. https://doi.org/10.1007/s11069-013-0781-0

Sivanpillai R, Jacobs KM, Mattilio CM, Piskorski E V. (2020) Rapid flood inundation mapping by differencing water indices from pre- and post-flood Landsat images. Front Earth Sci. https://doi.org/10.1007/s11707-020-0818-0

Tehrany MS, Kumar L, Jebur MN (2019a) Evaluating the application of the statistical index method in flood susceptibility mapping and its comparison with frequency ratio and logistic regression methods. Geomatics, Nat Hazards Risk 10:79-101. https://doi.org/10.1080/19475705.2018.1506509

Tehrany MS, Kumar L, Shabani F (2019b) A novel GIS-based ensemble technique for flood 
susceptibility mapping using evidential belief function and support vector machine: Brisbane , Australia. https://doi.org/10.7717/peerj.7653

Tehrany MS, Lee MJ, Pradhan B, et al (2014a) Flood susceptibility mapping using integrated bivariate and multivariate statistical models. Environ Earth Sci 72:4001-4015. https://doi.org/10.1007/s12665-014-3289-3

Tehrany MS, Pradhan B, Jebur MN (2014b) Flood susceptibility mapping using a novel ensemble weights-of-evidence and support vector machine models in GIS. J Hydrol 512:332-343. https://doi.org/10.1016/j.jhydrol.2014.03.008

Tehrany MS, Pradhan B, Mansor S, Ahmad N (2015) Catena Flood susceptibility assessment using GIS-based support vector machine model with different kernel types. Catena 125:91101. https://doi.org/10.1016/j.catena.2014.10.017

Tien D, Hoang N, Pham T, et al (2019) A new intelligence approach based on GIS-based Multivariate Adaptive Regression Splines and metaheuristic optimization for predicting fl ash fl ood susceptible areas at high-frequency tropical typhoon area. J Hydrol 575:314-326. https://doi.org/10.1016/j.jhydrol.2019.05.046

Tiryaki M, Karaca O (2018) Flood susceptibility mapping using GIS and multicriteria decision analysis : Saricay-Çanakkale ( Turkey )

Vafakhah M (2020) Comparing performance of random forest and adaptive neuro-fuzzy inference system data mining models for flood susceptibility mapping. 1-16

Vojtek M, Vojteková J (2016) Flood hazard and flood risk assessment at the local spatial scale : a case study. 5705:. https://doi.org/10.1080/19475705.2016.1166874 
1 Wanders N, Karssenberg D, De Roo A, et al (2014) The suitability of remotely sensed soil

2 moisture for improving operational flood forecasting. Hydrol Earth Syst Sci 18:2343-2357.

3 https://doi.org/10.5194/hess-18-2343-2014

4 Wang L, Sawada K, Moriguchi S (2011) Landslide susceptibility mapping by using logistic 5 regression model with neighborhood analysis: A case study in Mizunami city. Int J GEOMATE 1:99-104. https://doi.org/10.21660/2011.2.2c

7 Wang Y, Hong H, Chen W, et al (2019) Flood susceptibility mapping in Dingnan County (

8 China ) using adaptive neuro-fuzzy inference system with biogeography based optimization 9 and imperialistic competitive algorithm. J Environ Manage 247:712-729. 10 https://doi.org/10.1016/j.jenvman.2019.06.102

11 WHO (2019) Health Emergency and Disaster Risk Management: Overview

12 Yalcin G, Akyurek Z (2000) Analysing Flood Vulnerable Areas With Multicriteria Evaluation. 13 Methods 1-6

14 Youssef AM, Pradhan B, Hassan AM (2011) Flash flood risk estimation along the St. Katherine 15 road, southern Sinai, Egypt using GIS based morphometry and satellite imagery. Environ 16 Earth Sci 62:611-623. https://doi.org/10.1007/s12665-010-0551-1 
Figures
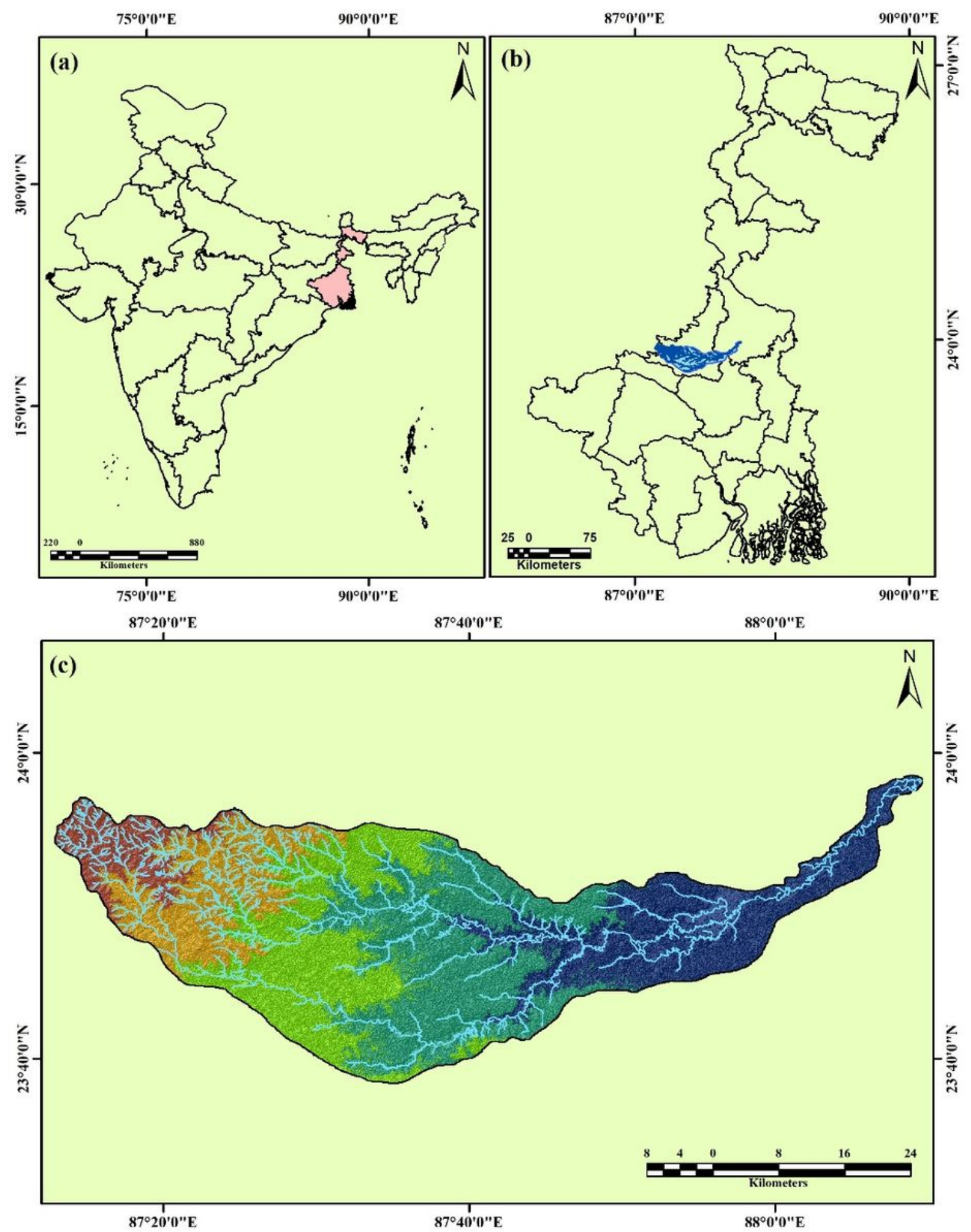

Figure 1

Location of the study area: a. India b. West Bengal c. Kopai river basin 


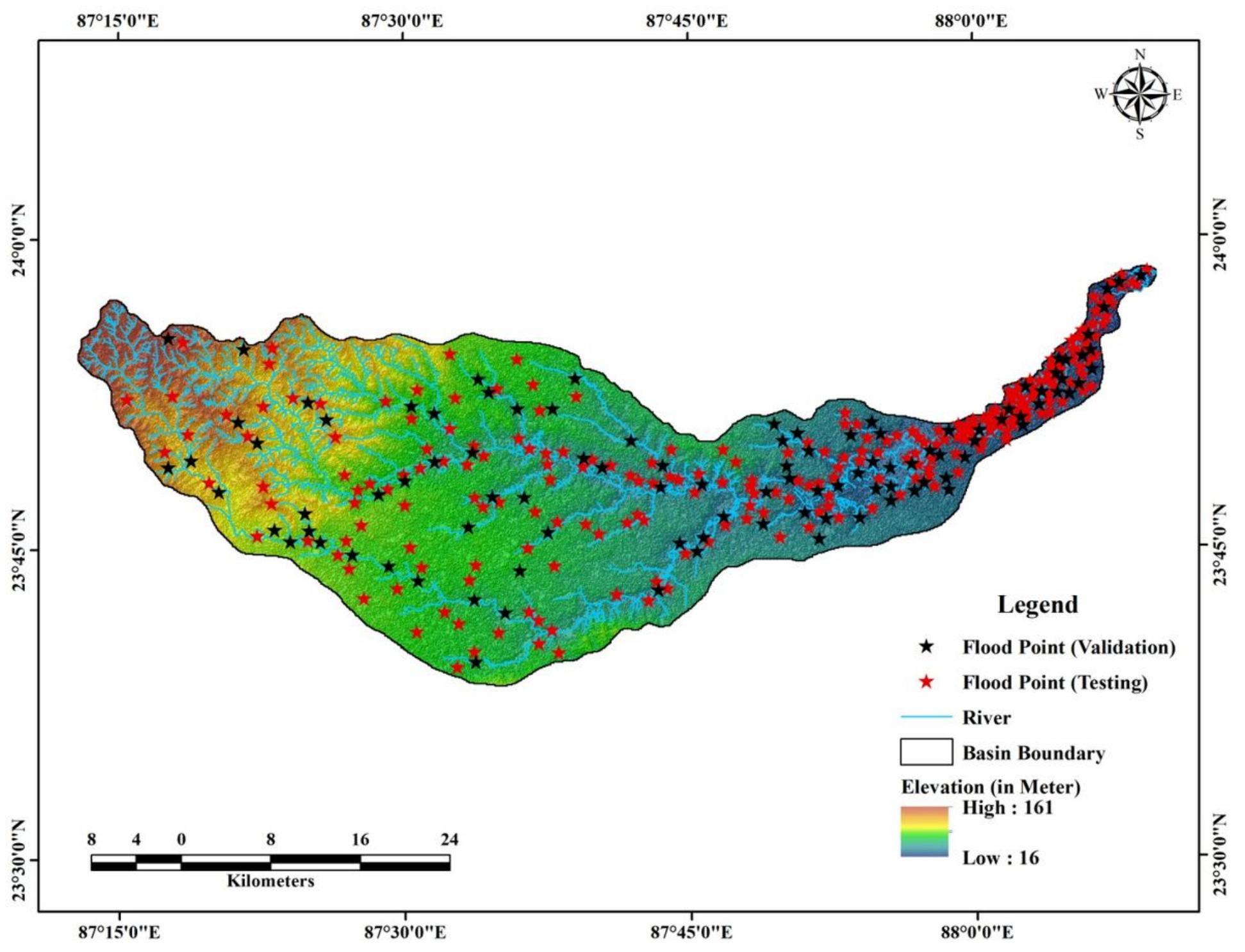

Figure 2

Flood inventory map 

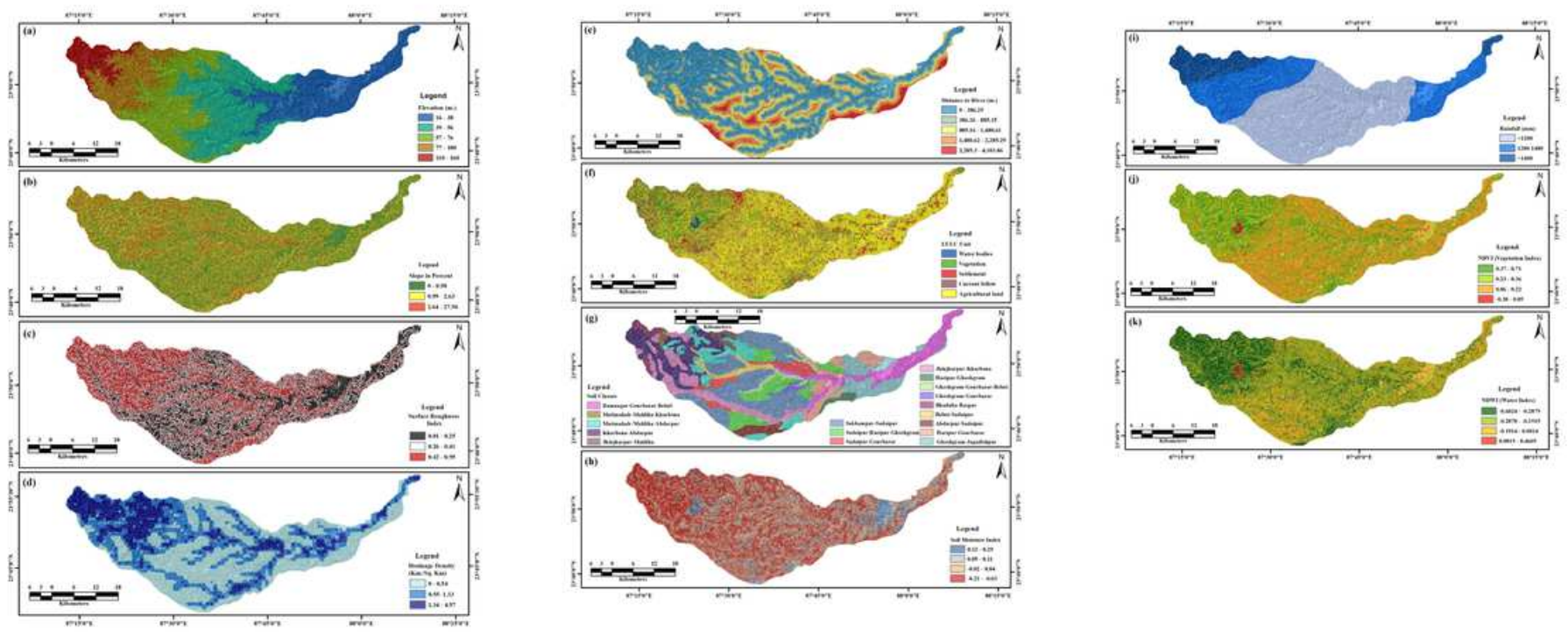

\section{Figure 3}

Input data: a. Elevation b. Slope c. Surface roughness d. Drainage density e. Distance from river $f$. Landuse/landcover g. Soil h. Soil moisture index i. Rainfall j. NDVI k. NDWI

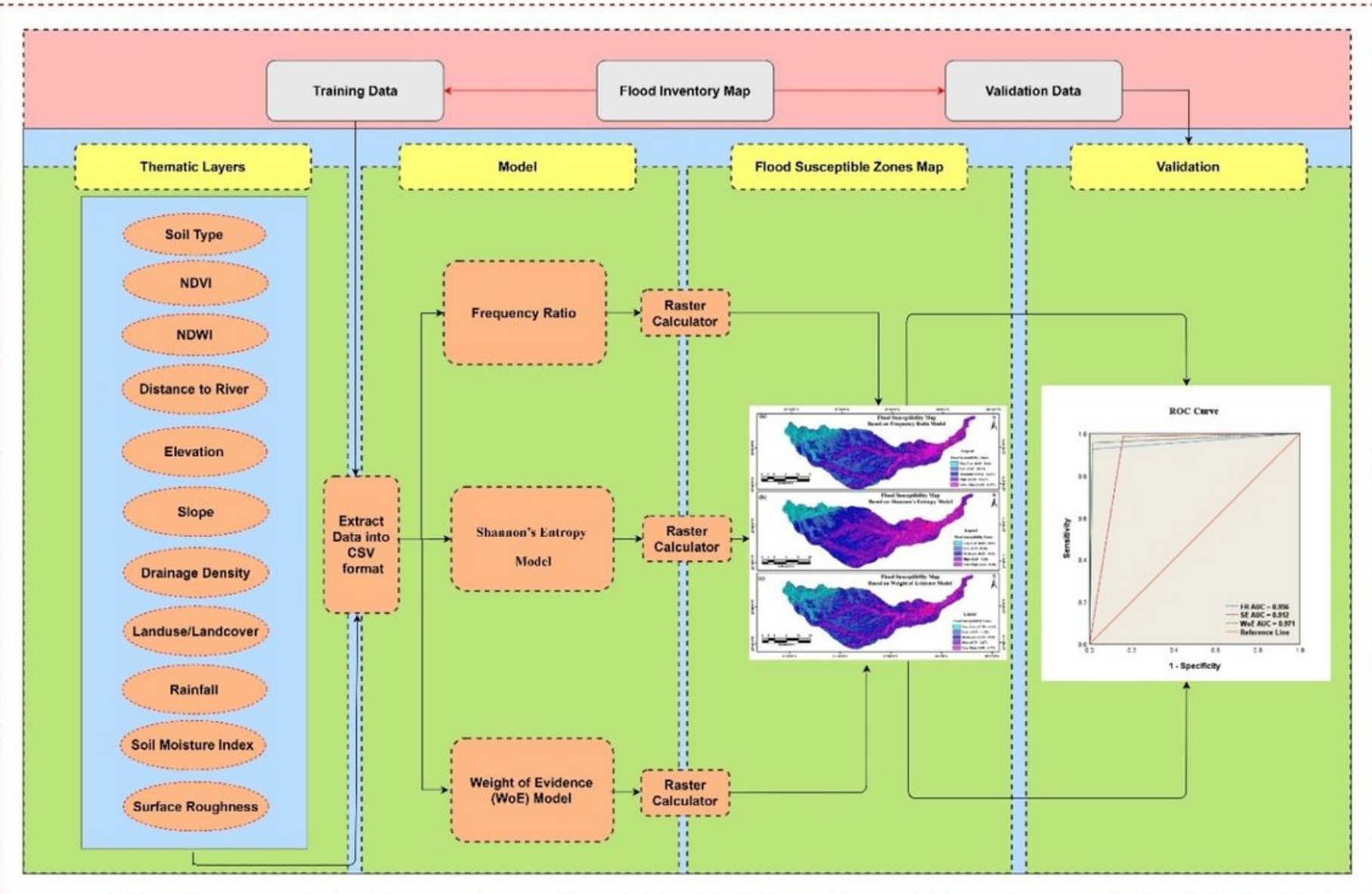

Figure 4 

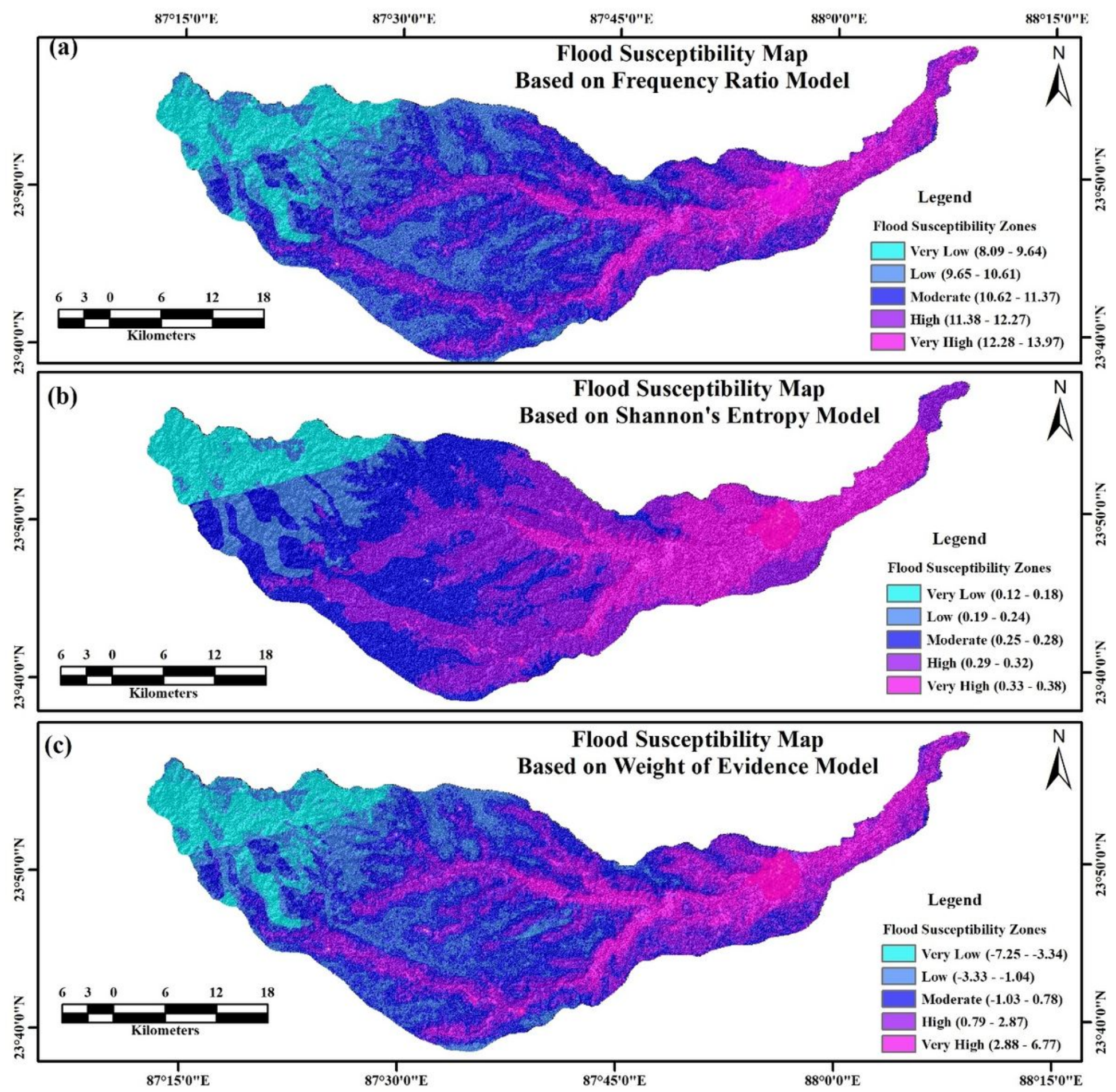

Figure 5

Flood susceptibility map based on (a) Frequency ratio (b) Shannon's entropy (c) Weight of evidence 


\section{ROC Curve}

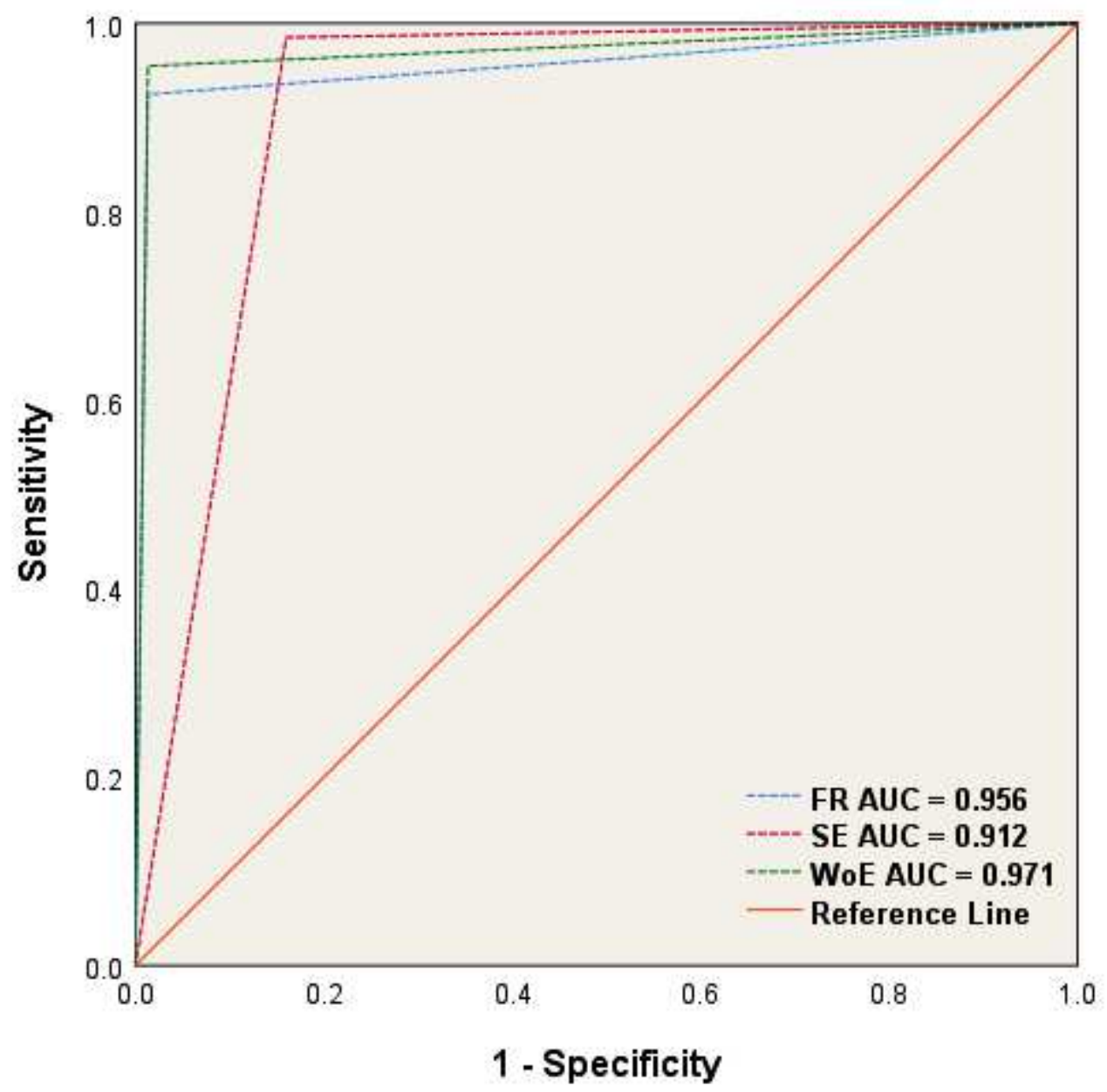

Figure 6

ROC for model validation

\section{Supplementary Files}

This is a list of supplementary files associated with this preprint. Click to download.

- Tables.docx 